Research Article

\title{
Elliptical Ring Antenna Excited by Circular Disc Monopole for UWB Communications
}

\author{
Krittaya Nakprasit $\mathbb{D}^{\mathrm{D}},{ }^{1}$ Arnon Sakonkanapong $\mathbb{D}^{\mathrm{D}},{ }^{2}$ and Chuwong Phongcharoenpanich $\mathbb{i D}^{2}$ \\ ${ }^{1}$ Faculty of Industrial Technology, Nakhon Ratchasima Rajabhat University, Nakhon Ratchasima, Thailand \\ ${ }^{2}$ Faculty of Engineering, King Mongkut's Institute of Technology Ladkrabang, Bangkok, Thailand \\ Correspondence should be addressed to Chuwong Phongcharoenpanich; chuwong.ph@kmitl.ac.th
}

Received 5 July 2019; Revised 25 November 2019; Accepted 13 January 2020; Published 17 February 2020

Academic Editor: Paolo Baccarelli

Copyright ( 2020 Krittaya Nakprasit et al. This is an open access article distributed under the Creative Commons Attribution License, which permits unrestricted use, distribution, and reproduction in any medium, provided the original work is properly cited.

This research proposes a compact elliptical ring antenna excited by a circular disc monopole (CDM) for ultra-wideband (UWB) communications. In the study, time- and frequency-domain pulse distortions of the antenna in the transmission mode were characterized by magnitude and phase of the antenna transfer function $\left(H_{\mathrm{rad}}\right)$. The results showed that the gain and magnitude of $H_{\text {rad }}$ in the boresight direction are sufficiently flat with linear phase response. The average antenna gain is $3.9 \mathrm{dBi}$ over the UWB spectrum. The antenna also exhibits low pulse distortion with the correlation factors $(\rho)$ of 0.98 and 0.93 for the fifth-order derivative Gaussian pulse and modulated Gaussian pulse with $6 \mathrm{GHz}$ band rejection. The CDM-excited elliptical ring antenna possesses several attractive features, including wide bandwidth, flat gain, compactness, low cost, and low distortion.

\section{Introduction}

Ultra-wideband (UWB) is a radio technology with a spectrum that occupies a fractional bandwidth greater than 20 percent of the center frequency, or a bandwidth of at least $500 \mathrm{MHz}$ when the center frequency is higher than $6 \mathrm{GHz}$. UWB emits less than $-41.3 \mathrm{dBm} / \mathrm{MHz}$ within the 3.1-10.6 GHz operating band. There are two UWB signal implementation schemes: impulse UWB (I-UWB) using the full spectrum of a single band for low-data-rate applications and multicarrier UWB (MC-UWB) using multiple subbands with a bandwidth larger than $500 \mathrm{MHz}$ in combination with orthogonal frequency-division multiplexing (OFDM) modulation for high-data-rate applications [1, 2]. The advantages of I-UWB include low complexity, low power consumption, and good time-domain resolution, allowing for location and tracking applications. I-UWB has also been incorporated in IEEE 802.15.4a standard for a lowrate wireless personal area network (LR-WPAN).

In impulse radio-based ultra-wideband communication, minimum impulse signal distortion is imperative because UWB antennas transmit very short pulses on the order of nanosecond in duration without carrier and occupies a very large bandwidth of 7.5 GHz. Therefore, UWB antennas should possess a clean impulse response (constant magnitude and linear phase) where the radiating signal is a time derivative of the input signal [2]. Most UWB antennas have an omnidirectional radiation pattern for applications in mobile devices.

Antennas with planar monopoles protruding from a perpendicular ground plane have been proposed in [3-9]. The antenna with a consistent monopole-like radiation characteristic was proposed [3]. The bandwidth is extremely larger than conventional monopole whip antenna. Next, the monocone antenna with a dielectric loading and a monocone quasi-Yagi antenna was subsequently investigated $[4,5]$. The very wideband operation could be achieved with a reasonable gain. In $[6,7]$, the UWB antennas with a reflector were presented for high gain and steerable beam purpose. The UWB patch antenna with a top loading was also designed for the WBAN system [8]. In [9], the UWB monopole-like radiation characteristic was introduced for high isolation between transmit and receive ports. Despite low profile structure, these antennas lack a compact size because of its extended ground plane structure. To obtain a more compact structure, the modified biconical antenna [10] and the coplanar waveguide (CPW)-feeding antennas 
[11-14] have been reported for some specific applications. In addition, the printed antennas with different structures in both sides had been realized for bandwidth enhancement size miniaturizations [15-19]. The main advantage of these antennas is that the flat structure could be readily integrated into electronic circuits. However, they suffer from bulkiness because of the presence of the planar ground plane.

This study proposes an elliptical ring antenna excited by a circular disc monopole (CDM) for radiation over the UWB spectrum. The antenna is compact and consists of a simple feeder and low-cost components. In the antenna development, simulations were carried out using CST Studio Suite [20], and a prototype antenna was fabricated. To validate the antenna performance, time- and frequencydomain pulse distortions in the transmission mode in terms of magnitude and phase of the antenna transfer function $\left(H_{\mathrm{rad}}\right)$ were characterized by manipulating the angular positions. The fifth-order derivative Gaussian pulse and modulated Gaussian pulse with $6 \mathrm{GHz}$ band rejection were used as the exciting signals in the simulation. The correlation factors between input and radiated pulses were also determined.

\section{Antenna Design and Parametric Study}

Figure 1 illustrates the proposed antenna, consisting of an elliptical ring and a CDM, where $a, b, d$, and $l$ are the semimajor axis, semiminor axis, thickness, and length of the elliptical ring, respectively; and $c$ and $t$ are the radius and thickness of the CDM, respectively, with a feeding gap of $h$ between the elliptical ring and the CDM. The CDM radiates omnidirectionally with wideband characteristics, and the elliptical ring transforms the omnidirectional into bidirectional radiation pattern. A hole was centrally drilled at the base of the elliptical ring, whose radius is identical to the dielectric radius of an SMA connector to connect the antenna to the connector.

To overcome bulkiness, the feeding gap $(h)$, the CDM thickness $(t)$, and the ring length $(l)$ were $1 \mathrm{~mm}$. Based on the length of quarter-wave monopole operating at $3 \mathrm{GHz}$, the initial CDM diameter was $25 \mathrm{~mm}(c=12.5 \mathrm{~mm})$.

Initially, the simulation was carried out using a circular ring, where $a=b$. The feeding gap $(h)$ was optimized to prevent electrical short circuit. As a result, $h$ was $1 \mathrm{~mm}$ and the radius of the circular ring was $14 \mathrm{~mm}$. The parameters of the circular ring antenna are tabulated in Table 1 . However, these parameters failed to achieve $\left|S_{11}\right|<-10 \mathrm{~dB}$ across the UWB spectrum, as shown in Figure 2. In the figure, with the circular ring, the impedance matching $\left(\left|S_{11}\right|\right)$ was achieved slightly above $7 \mathrm{GHz}$ and again $10.66 \mathrm{GHz}$, failing to cover the entire UWB spectrum. As shown in Figure 2, to cover the UWB spectrum with the circular ring, a large ground plane of $100 \mathrm{~mm} \times 100 \mathrm{~mm}$ was required. To achieve size compactness, the large ground plane is undesirable. The CDMexcited elliptical ring is proposed to accomplish UWB operation without using a large ground plane. The radius of $\mathrm{CDM}(c)$ and the dimension of elliptical ring axes $(a$ and $b$ ) are varied to cover the UWB frequency range.

To realize the size compactness with UWB characteristics, the parameters were individually varied and simulated

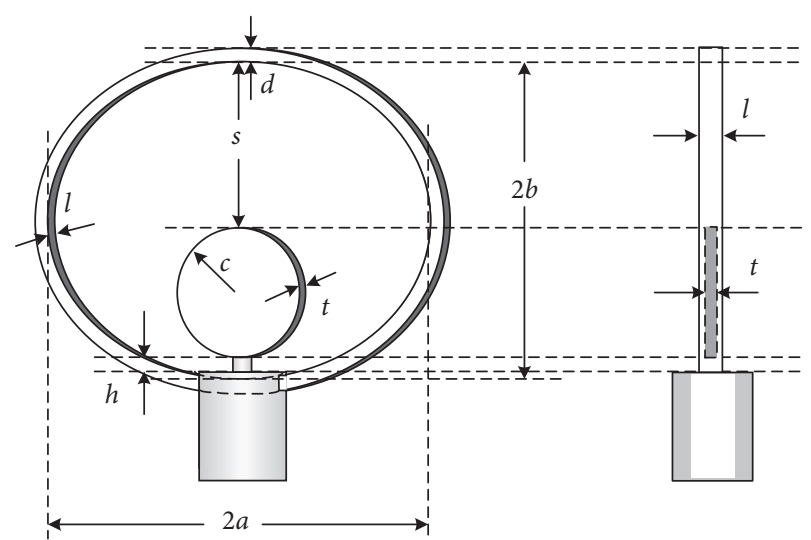

FIgURE 1: Schematic of the elliptical ring antenna excited by the circular disc monopole.

TABle 1: Parameters of CDM-excited circular and elliptical ring antennas.

\begin{tabular}{lcc}
\hline Parameters & $\begin{array}{c}\text { Initial size }(\mathrm{mm}) \\
\text { (circular ring) }\end{array}$ & $\begin{array}{c}\text { Refined size }(\mathrm{mm}) \\
\text { (elliptical ring) }\end{array}$ \\
\hline $\begin{array}{l}\text { Semimajor axis of the } \\
\text { elliptical ring }(a)\end{array}$ & 14.0 & 13.0 \\
$\begin{array}{l}\text { Semiminor axis of the } \\
\text { elliptical ring }(b)\end{array}$ & 14.0 & 11.0 \\
$\begin{array}{l}\text { Ring length }(l) \\
\text { Thickness of the elliptical }\end{array}$ & 1.0 & 1.0 \\
ring $(d)$ & 1.0 & 1.0 \\
Radius of CDM $(c)$ & 12.5 & 6.5 \\
Thickness of CDM $(t)$ & 1.0 & 1.0 \\
Feeding gap $(h)$ & 1.0 & 1.0 \\
Spacing between the \\
elliptical ring and CDM
\end{tabular}

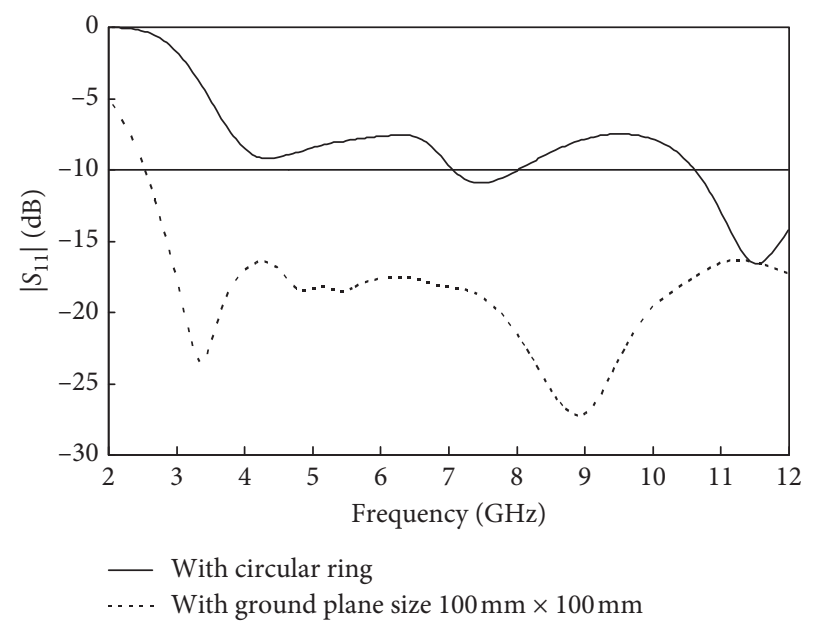

FIgURE 2: Simulated $\left|S_{11}\right|$ of CDM with the circular ring and with the ground plane.

$\left|S_{11}\right|$ determined. Figure 3 shows the simulated $\left|S_{11}\right|$ under varying a (11-15 $\mathrm{mm})$, given the other antenna refined parameters remaining constant.

Figures 4-8 illustrate the simulated $\left|S_{11}\right|$ under varying $b$, $l, d, t$, and $h$, respectively, given the other parameters 


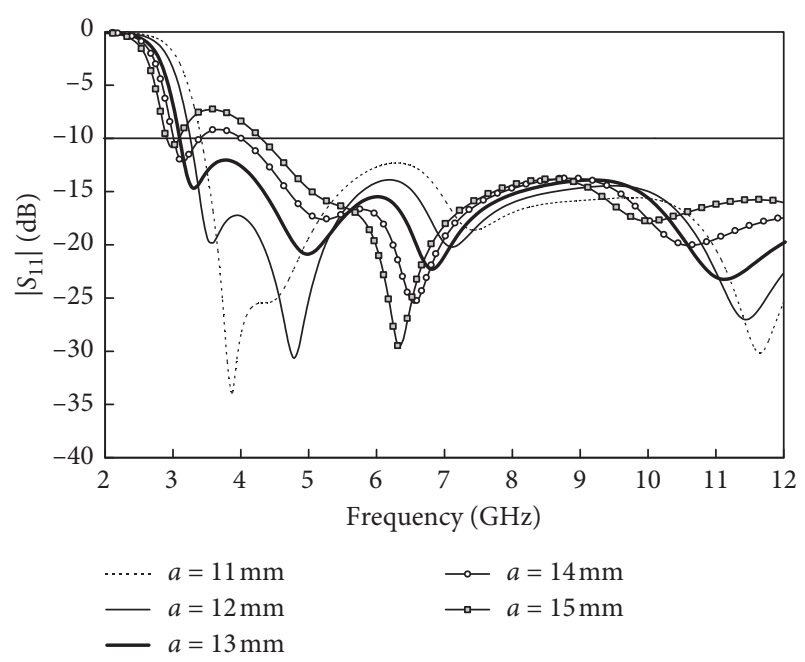

FIGURE 3: Simulated $\left|S_{11}\right|$ under variable $a$ of $11,12,13,14$, and $15 \mathrm{~mm}$, given the other parameters remaining constant.

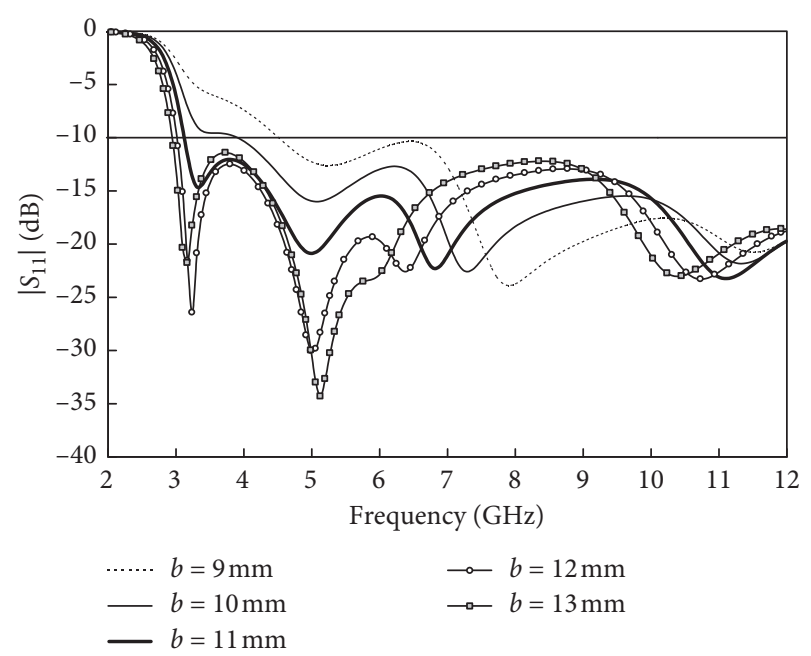

FIGURE 4: Simulated $\left|S_{11}\right|$ under varying $b$ of $9,10,11,12$, and $13 \mathrm{~mm}$.

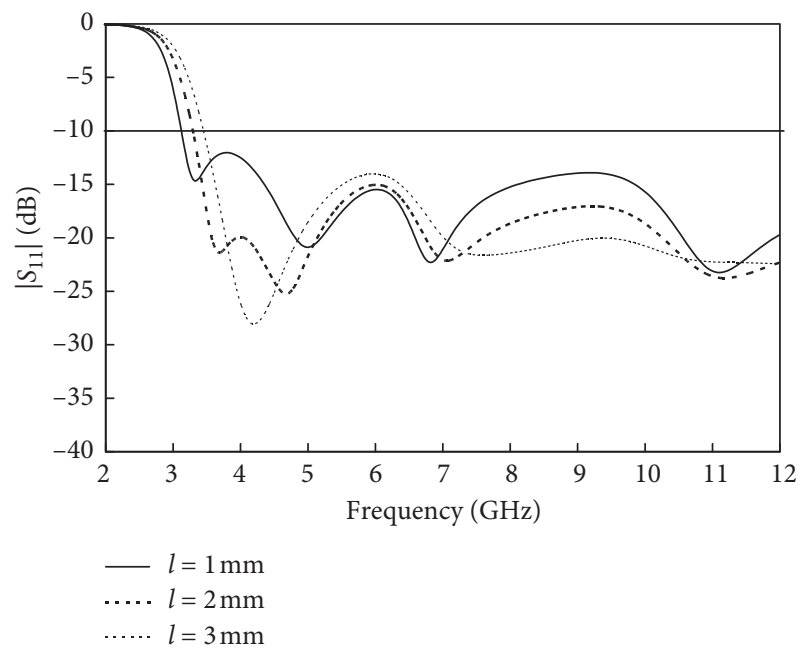

FIgURE 5: Simulated $\left|S_{11}\right|$ under varying $l$ of 1,2 , and $3 \mathrm{~mm}$.

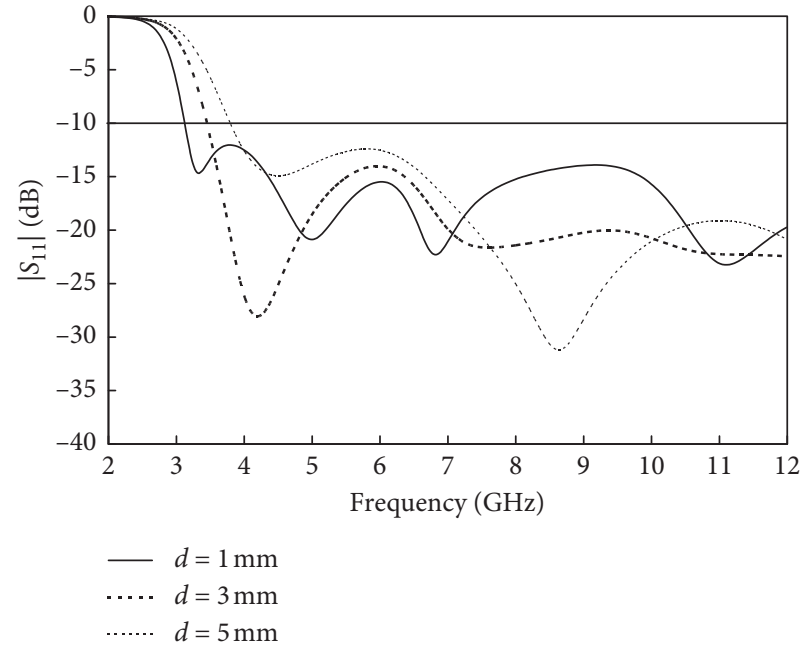

FIgURE 6: Simulated $\left|S_{11}\right|$ under varying $d$ of 1,3 , and $5 \mathrm{~mm}$.

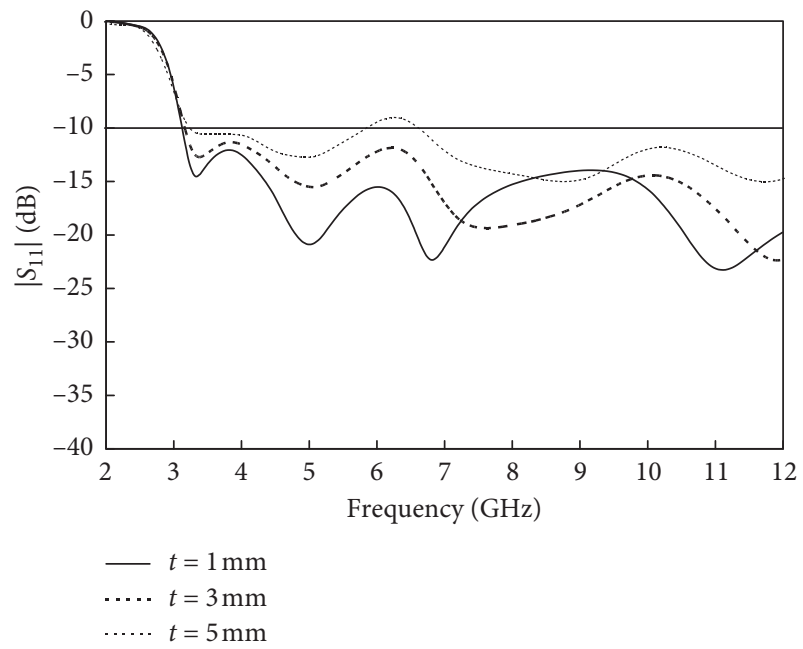

Figure 7: Simulated $\left|S_{11}\right|$ under varying $t$ of 1,3 , and $5 \mathrm{~mm}$.

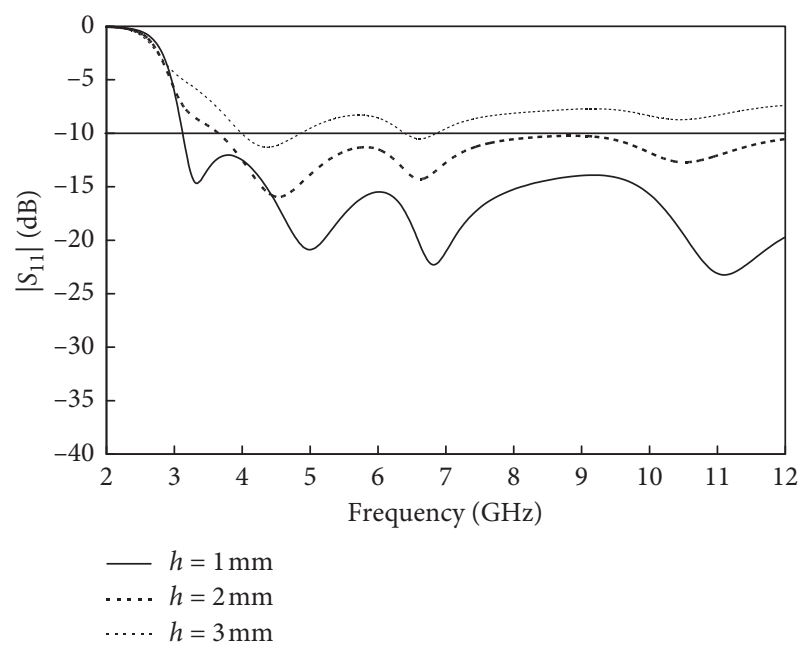

FIgURE 8: Simulated $\left|S_{11}\right|$ under varying $h$ of 1,2 , and $3 \mathrm{~mm}$. 


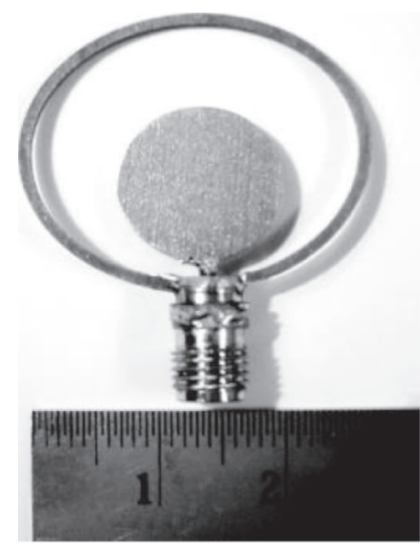

(a)

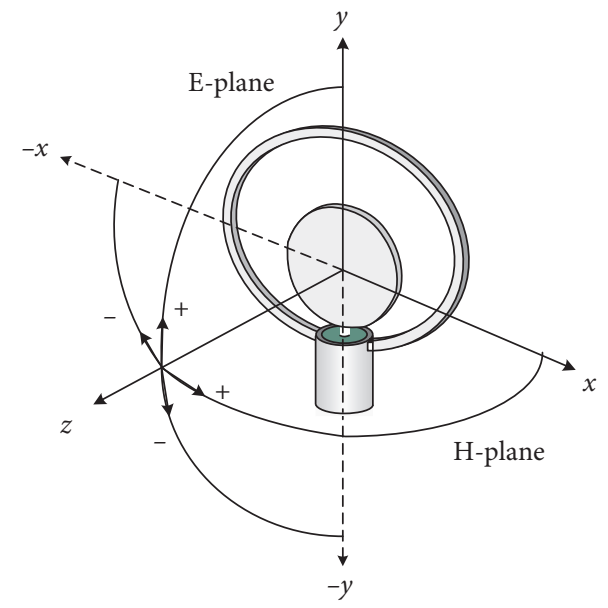

(b)

Figure 9: Prototype antenna and the coordinate system of the antenna. (a) Prototype antenna. (b) Coordinate system.

remaining unchanged (Table 1). The results validate the elliptical ring antenna parameters.

\section{Antenna Characteristics}

A prototype antenna was fabricated according to the elliptical ring antenna refined parameters in Table 1. Figures 9(a)-9(b) show the prototype antenna and the coordinate system. In Figure 10, the simulated and measured results showed that the bandwidth of the antenna covered the entire UWB spectrum. Instead of using the $\mathrm{CDM}$ with the ground plane size $100 \mathrm{~mm} \times 100 \mathrm{~mm}$, the proposed antenna using the CDM-excited elliptical ring can also cover UWB with a compact size. The discrepancy could be attributed to the coupling effects of the connecting cable.

Ideally, the antenna gain is flat under the distortionless condition [21]. Figure 11 shows the simulated gain in the boresight direction, varying between 3.1 and $4.8 \mathrm{dBi}$ $(<3 \mathrm{dBi})$, indicating flat gain. The average simulated gain is $3.9 \mathrm{dBi}$ along the UWB spectrum. Because the proposed antenna contained no dielectric materials, it achieved very high radiation efficiency (almost 100\%) along the UWB spectrum.

The CDM-excited elliptical ring antenna radiated bidirectionally over $3.1-10.6 \mathrm{GHz}$. The measurement setup for the radiation pattern are shown in Figure 12. The standard horn antenna ETS model 3115 is used as the transmitting antenna, and the antenna under test (AUT) is used as the receiving antenna. The distance between the antennas are maximized for closed to uniform plane wave. The position of the AUT is located by line-of-sight alignment. The radiation pattern measured results at a frequency of $3.1 \mathrm{GHz}, 6.8 \mathrm{GHz}$, and $10.6 \mathrm{GHz}$ were carried out by E- and $\mathrm{H}$-planes. The comparison between simulated and measured radiation patterns are shown in Figures 13(a)-13(c). Table 2 presents the main beam direction and half-power beamwidth (HPBW) of the antenna. A plus sign indicates that the main beam is tilting upward from $z$ to $+y$ axis, and a minus sign

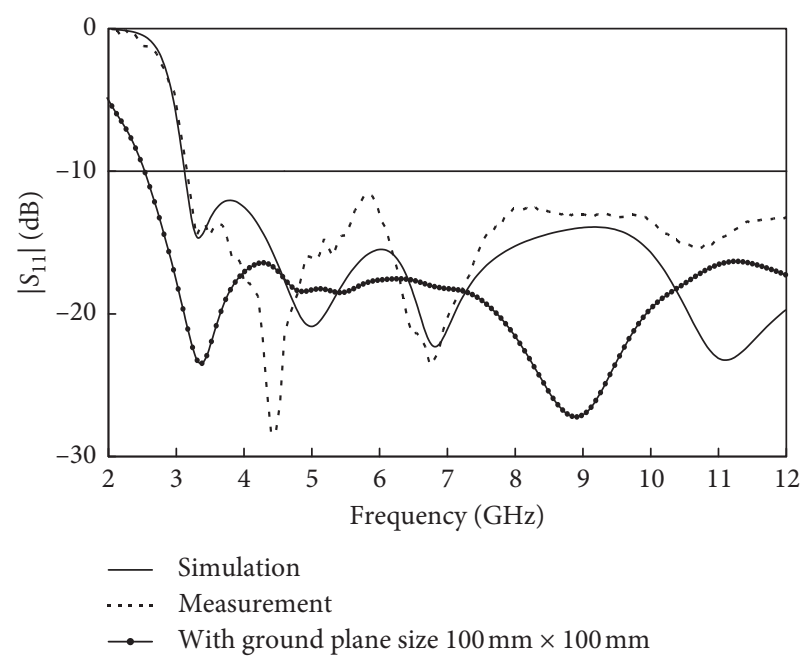

Figure 10: $\left|S_{11}\right|$ versus frequency of the antenna.

indicates that the main beam is tilting downward in the direction of $-y$ axis.

The main beam direction is influenced by the induced electric fields from various antenna components. Figure 14 shows the contour with color map and excitation levels of electric fields on the $z$-plane $(5 \mathrm{~mm})$ at the boresight of the antenna aperture. From $3.1 \mathrm{GHz}$ to $6.8 \mathrm{GHz}$, the induced electric fields in the direction perpendicular to the $z$ axis (between the top of the CDM and the top of the ring) continually increased, resulting in a downward tilted main beam (Figure 14(a)). At $6.8 \mathrm{GHz}$ (the center frequency), the electric fields mostly radiated without induced electromagnetic fields at the top and bottom of the elliptical ring, as shown in Figure 14(b). Therefore, the main beam was in the boresight direction. At $10.6 \mathrm{GHz}$, stronger induced electric fields near the feeding point and the connector were observed in the direction perpendicular to the $z$ axis, resulting in an upward tilted main beam (Figure 14(c)). The main beam in E-plane was tilted upward as the frequency increased from $6.8 \mathrm{GHz}$ to $10.6 \mathrm{GHz}$. 


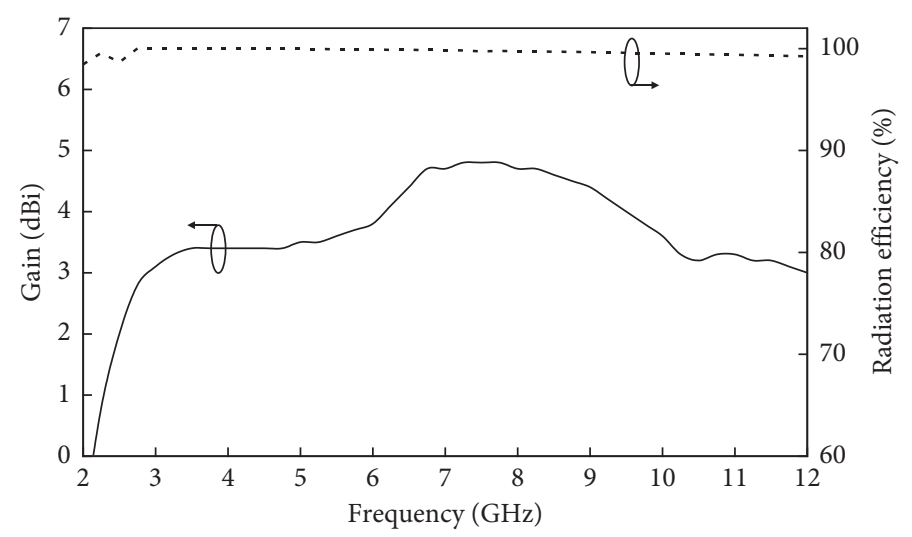

FIGURE 11: Gain and radiation efficiency versus frequency of the antenna.

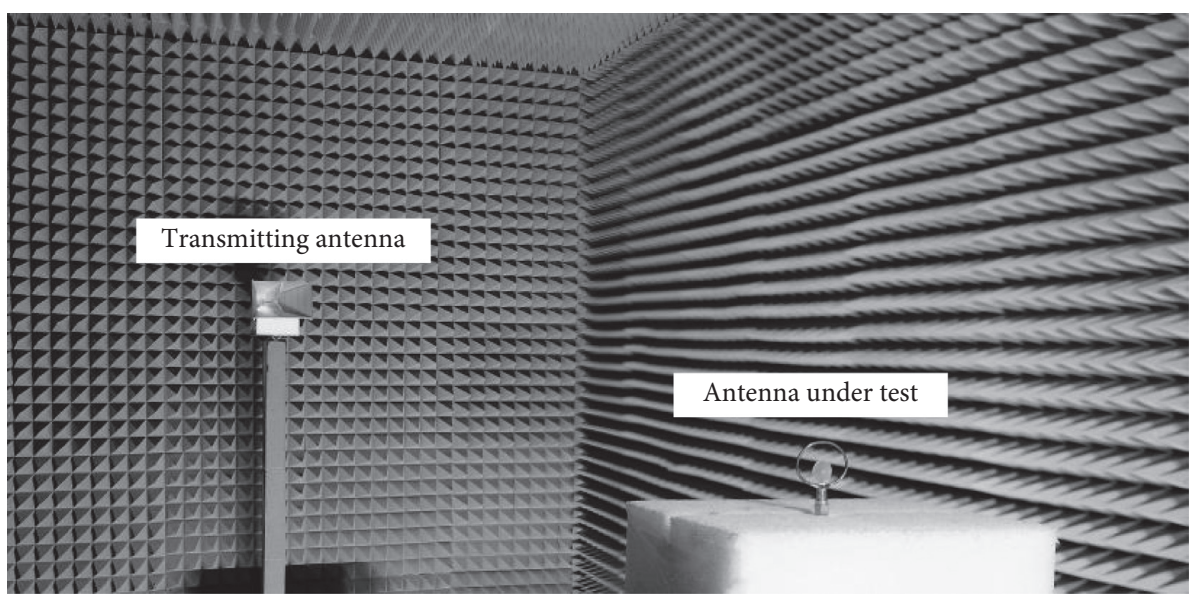

FIGURE 12: Radiation pattern measurement setup in the anechoic chamber.

The boresight direction, however, remained in the HPBW region, resulting in bidirectional radiation over the UWB spectrum. The cross polarization is also very low in the boresight direction.

Table 3 provides a comparison between the performance of this antenna with the current state of the art in UWB antennas. These antennas were designed to meet the application requirements with a very wideband frequency range and desirable radiation characteristics. Furthermore, the low profile and size compactness are important features for actual applications.

The antennas with a flat ground plane or reflector are low profile at the expense of a large planar dimension [3-9]. The modified biconical antenna [10] without a flat ground plane can overcome the bulky ground plane. However, the antenna volume is relatively huge. The patch antennas using a printed circuit board (PCB) [11-19] that can accommodate the radiator and ground plane within the single structure such as coplanar waveguide (CPW), strip line, and partial ground plane can reduce the overall antenna size with the suffered gain limitation. Apparently, the antenna presented in this work is compact with a very wide impedance bandwidth and efficient gain.

\section{Antenna Performance for UWB Communications}

The performance of the UWB antenna could be assessed by pulse distortion attributable to the effect of the propagation path. In this research, the magnitude and phase of the antenna transfer function $\left(H_{\mathrm{rad}}\right)$ were characterized at different angular positions of a receiving probe in E-plane and H-plane. The angular position $(\theta)$ and probe direction $(+$ and -) along E-plane and $\mathrm{H}$-plane were illustrated in Figure 9(b).

Figure 15 shows the simulated magnitude and phase of $H_{\text {rad }}$ in the boresight direction, given an antenna/probe propagation distance of $9.7 \mathrm{~cm}$ (in the far-field region). $\left|H_{\mathrm{rad}}\right|$ was normalized to remove the effect of the propagation distance. The normalized $\left|H_{\mathrm{rad}}\right|$ is sufficiently flat with $1.9 \mathrm{~dB}$ variation over the UWB spectrum. The phase of $H_{\mathrm{rad}}$ is of linear phase response, independent of propagation distance and time as the cycles of phase variation are proportionate to distance and time. Figures $16-18$ illustrate $\left|H_{\text {rad }}\right|$ at various angular positions in E-plane and H-plane.

The E-plane of the antenna is nonsymmetrical, so the plus and minus signs are used to indicate the direction. 


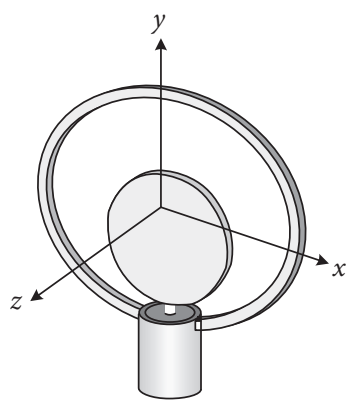

(a)

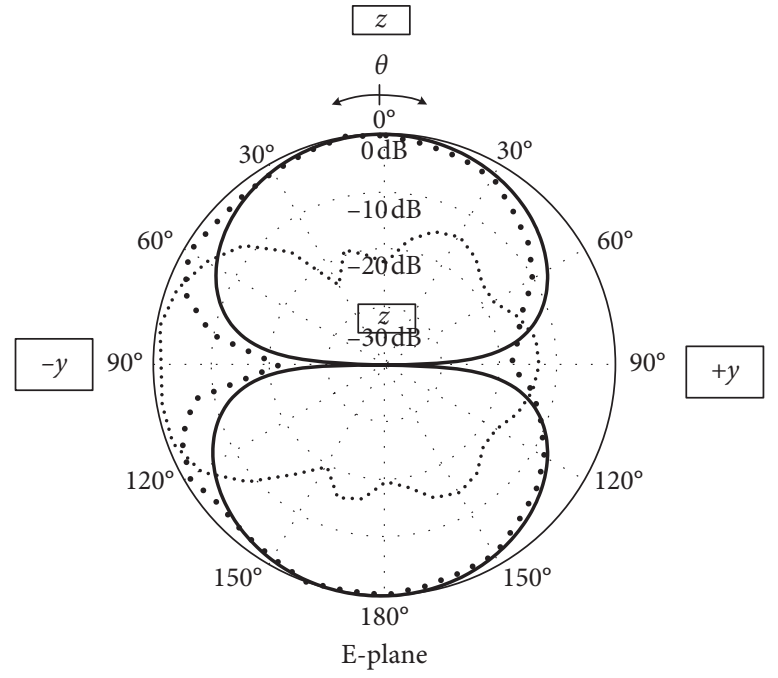

— Simulated co-polarization -.--- Simulated cross-polarization

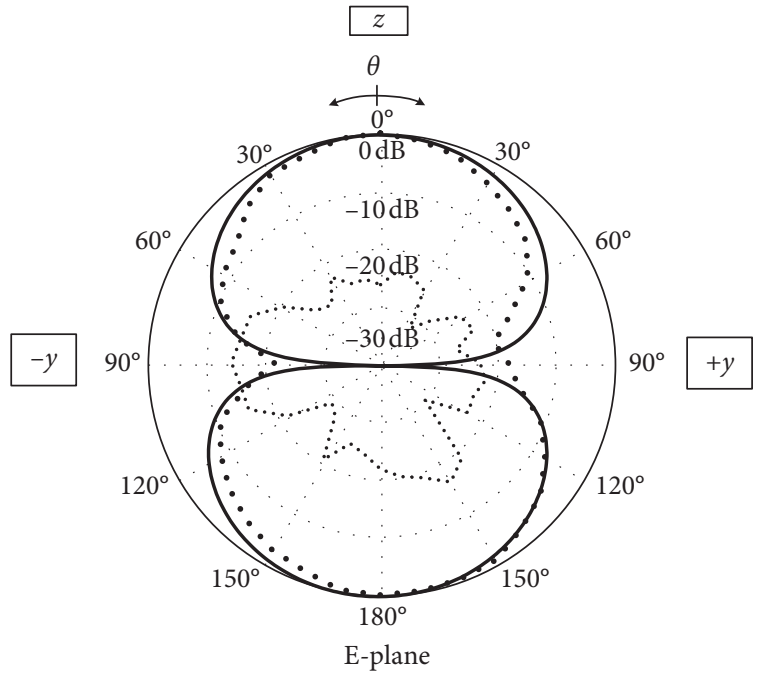

- Simulated co-polarization ----- Simulated cross-polarization

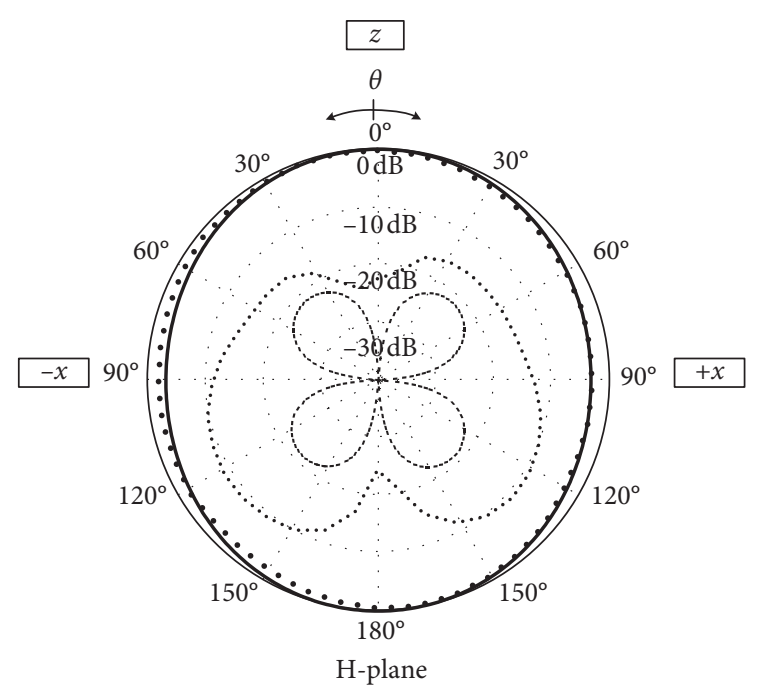

..... Measured co-polarization

.... Measured cross-polarization

(b)

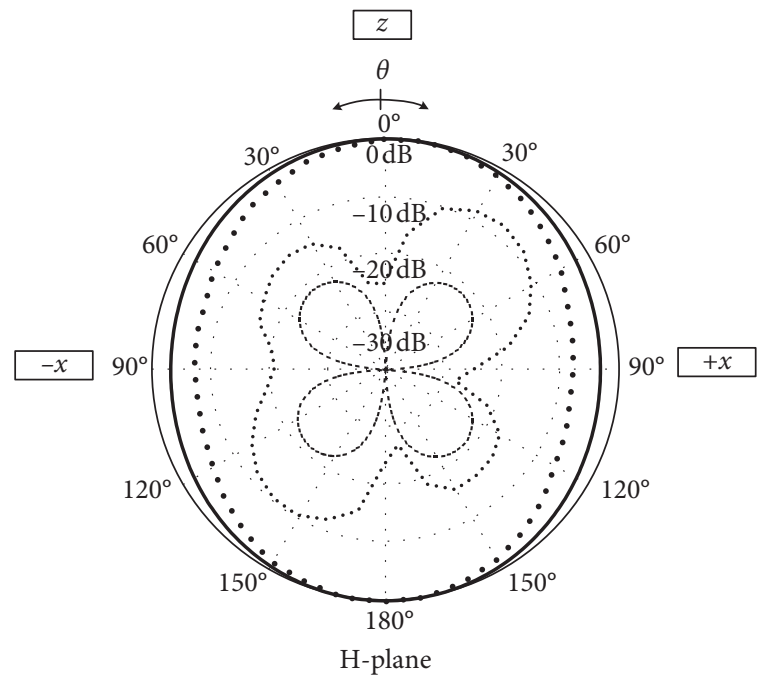

..... Measured co-polarization

.... Measured cross-polarization

(c)

Figure 13: Continued. 

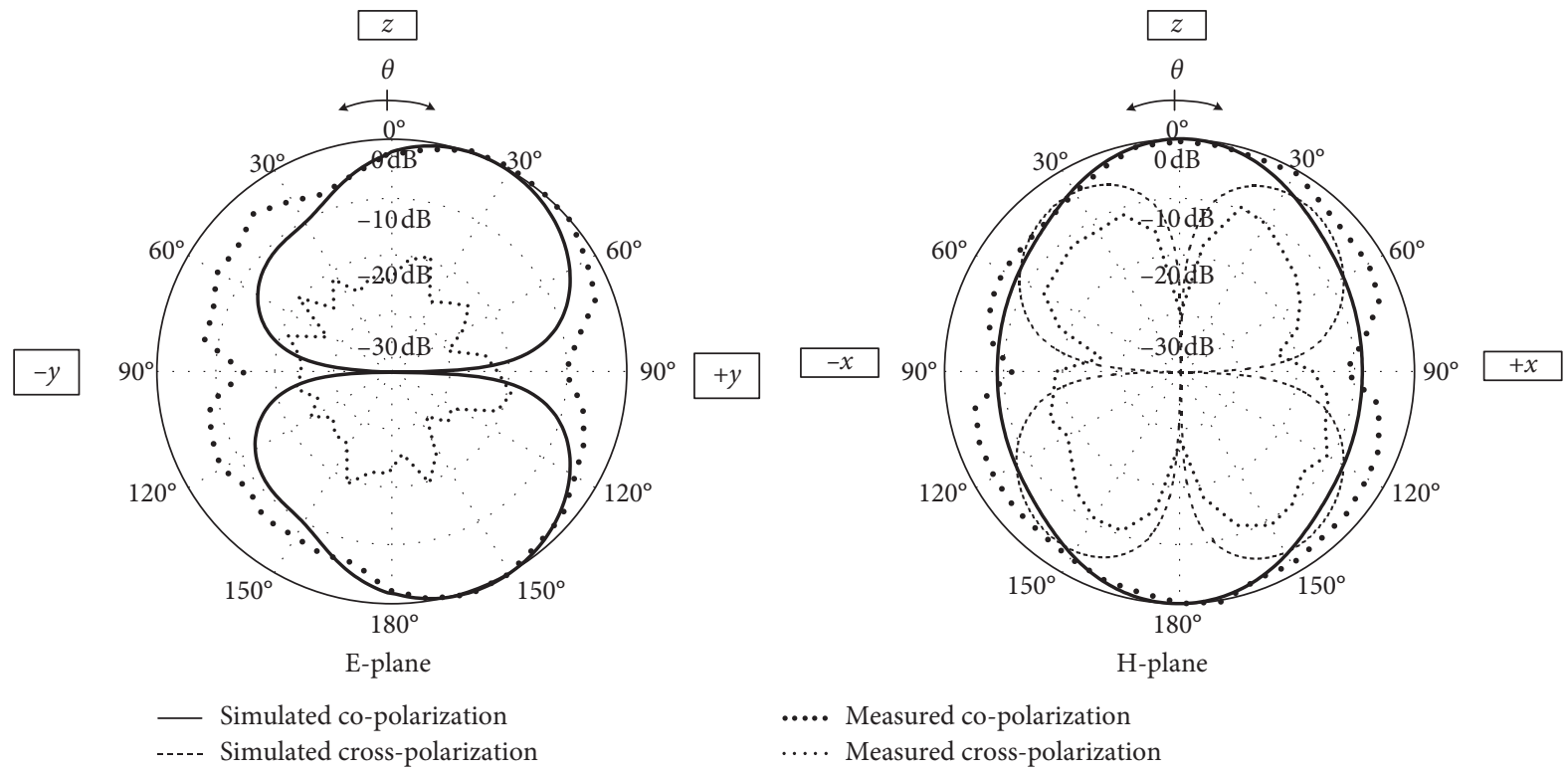

(d)

Figure 13: Radiation patterns of the antenna. (a) Antenna geometry (b) $3.1 \mathrm{GHz}$. (c) $6.8 \mathrm{GHz}$. (d) $10.6 \mathrm{GHz}$.

TABle 2: Radiation characteristics of the CDM-excited elliptical ring antenna.

\begin{tabular}{lcccc}
\hline $\begin{array}{l}\text { Frequency } \\
(\mathrm{GHz})\end{array}$ & $\begin{array}{c}\text { Main beam direction in } \\
\text { E-plane }(\mathrm{deg})\end{array}$ & $\begin{array}{c}\text { Main beam direction in } \\
\text { H-plane }(\mathrm{deg})\end{array}$ & $\begin{array}{c}\text { HPBW in } \\
\text { E-plane }(\mathrm{deg})\end{array}$ & $\begin{array}{c}\text { HPBW in } \\
\text { H-plane }(\mathrm{deg})\end{array}$ \\
\hline 3 & -4 & 0 & 84 & 80 \\
4 & -6 & 0 & 76 & 149 \\
5 & -8 & 0 & 68 & 177 \\
6 & -12 & 0 & 68 & 178 \\
7 & +4 & 0 & 59 & 103 \\
8 & +10 & 0 & 53 & 117 \\
9 & +12 & 0 & 53 & 73 \\
10 & +16 & 0 & 53 & 77 \\
\hline
\end{tabular}

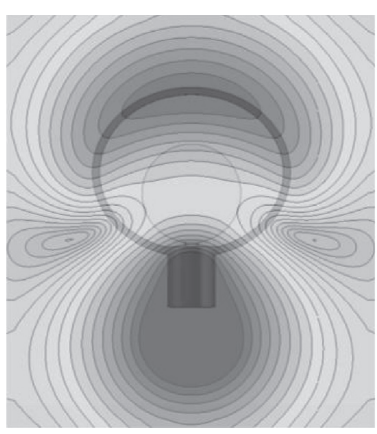

(a)

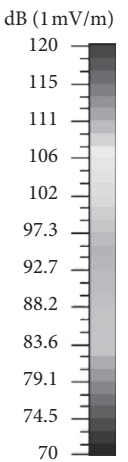

FIgURE 14: Electric fields near the antenna aperture.

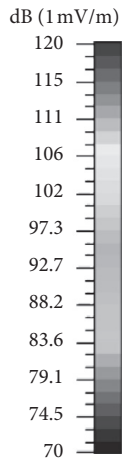

(b)
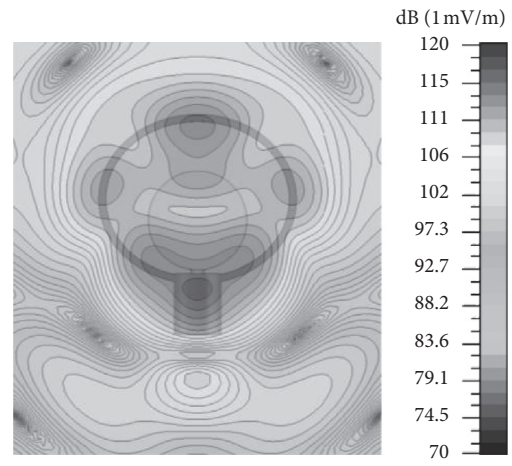

(c)

(a) $3.1 \mathrm{GHz}$. (b) $6.8 \mathrm{GHz}$. (c) $10.6 \mathrm{GHz}$.

Meanwhile, the H-plane is symmetrical. The flat magnitude and linear phase were observed over the UWB spectrum in the boresight direction but deteriorated outside the boresight direction.

In Figure 16, the pulse distortion in $\mathrm{H}$-plane evidently increased beyond $6 \mathrm{GHz}$ and became more pronounced with larger angles. This could be attributed to the fact that beyond $6 \mathrm{GHz}$, the electric fields in the area between the CDM and the elliptical ring were induced.

In Figure 17, the pulse distortion in E-plane in the upward direction was observed around $6 \mathrm{GHz}$ and became less severe afterward. The phenomenon could be attributed 
TABLE 3: Comparison of the performance of the proposed antenna with the current state of the art in UWB antennas.

\begin{tabular}{|c|c|c|c|c|}
\hline Reference & Electrical size & Frequency range $(\mathrm{GHz})$ & Fractional bandwidth (\%) & Gain $(\mathrm{dBi})$ \\
\hline$[3]$ & $0.27 \lambda_{\mathrm{L}} \times 0.27 \lambda_{\mathrm{L}} \times 0.040 \lambda_{\mathrm{L}}$ & $0.66-5.60$ & 157.83 & $4.0-8.0$ \\
\hline [4] & $4.68 \lambda_{\mathrm{L}} \times 4.68 \lambda_{\mathrm{L}} \times 0.214 \lambda_{\mathrm{L}}$ & $2.41-7.98$ & 107.22 & $1.0-2.5$ \\
\hline [5] & $1.86 \lambda_{\mathrm{L}} \times 3.1 \lambda_{\mathrm{L}} \times 0.072 \lambda_{\mathrm{L}}^{\mathrm{L}}$ & $6.20-18.00$ & 97.52 & $3.2-10.1$ \\
\hline [6] & $0.88 \lambda_{\mathrm{L}} \times 0.88 \lambda_{\mathrm{L}} \times 0.216 \lambda_{\mathrm{L}}$ & $2.20-6.50$ & 98.85 & $7.0-10.0$ \\
\hline [7] & $0.98 \lambda_{\mathrm{L}} \times 0.98 \lambda_{\mathrm{L}} \times 0.383 \lambda_{\mathrm{L}}$ & $1.66-11.00$ & 147.55 & $8.7-18.9$ \\
\hline [8] & $0.67 \lambda_{\mathrm{L}} \times 0.67 \lambda_{\mathrm{L}} \times 0.050 \lambda_{\mathrm{L}}$ & $2.50-24.00$ & 162.26 & $3.5-10.0$ \\
\hline [9] & $0.35 \lambda_{\mathrm{L}} \times 0.35 \lambda_{\mathrm{L}} \times 0.242 \lambda_{\mathrm{L}}$ & $0.58-1.75$ & 100.43 & $3.6-5.5$ \\
\hline [10] & $0.29 \lambda_{\mathrm{L}} \times 0.29 \lambda_{\mathrm{L}} \times 0.270 \lambda_{\mathrm{L}}$ & $1.50-41.00$ & 185.88 & $1.2-4.7$ \\
\hline [11] & $0.42 \lambda_{\mathrm{L}} \times 0.42 \lambda_{\mathrm{L}} \times 0.013 \lambda_{\mathrm{L}}$ & $2.50-12.0$ & 131.03 & $2.0-6.0$ \\
\hline [12] & $0.21 \lambda_{\mathrm{L}} \times 0.29 \lambda_{\mathrm{L}} \times 0.004 \lambda_{\mathrm{L}}$ & $3.10-10.60$ & 109.49 & $-1.0-3.0$ \\
\hline [13] & $0.21 \lambda_{\mathrm{L}} \times 0.25 \lambda_{\mathrm{L}} \times 0.013 \lambda_{\mathrm{L}}$ & $2.38-11.80$ & 132.86 & $2.8-5.6$ \\
\hline [14] & $0.19 \lambda_{\mathrm{L}} \times 0.27 \lambda_{\mathrm{L}} \times 0.002 \lambda_{\mathrm{L}}$ & $2.85-11.85$ & 122.45 & $-1.2-3.2$ \\
\hline [15] & $0.47 \lambda_{\mathrm{L}} \times 0.53 \lambda_{\mathrm{L}} \times 0.004 \lambda_{\mathrm{L}}$ & $3.10-10.60$ & 109.49 & $2.0-5.5$ \\
\hline [16] & $0.28 \lambda_{\mathrm{L}} \times 0.30 \lambda_{\mathrm{L}} \times 0.015 \lambda_{\mathrm{L}}$ & $2.80-12.00$ & 124.32 & $4.0-5.0$ \\
\hline [17] & $0.24 \lambda_{\mathrm{L}} \times 0.36 \lambda_{\mathrm{L}} \times 0.015 \lambda_{\mathrm{L}}$ & $2.90-10.80$ & 115.33 & $1.00-4.25$ \\
\hline [18] & $0.46 \lambda_{\mathrm{L}} \times 0.43 \lambda_{\mathrm{L}} \times 0.019 \lambda_{\mathrm{L}}$ & $3.50-11.70$ & 107.89 & $4.33-6.00$ \\
\hline [19] & $1.10 \lambda_{\mathrm{L}} \times 1.20 \lambda_{\mathrm{L}} \times 0.005 \lambda_{\mathrm{L}}$ & $2.99-10.00$ & 107.93 & $2.6-6.0$ \\
\hline Proposed antenna & $0.23 \lambda_{\mathrm{L}} \times 0.27 \lambda_{\mathrm{L}} \times 0.010 \lambda_{\mathrm{L}}$ & $3.10-12.00$ & 117.88 & $3.1-4.8$ \\
\hline
\end{tabular}

$\lambda_{\mathrm{L}}$ : the free-space wavelength corresponding to the lowest operating frequency of the antenna.

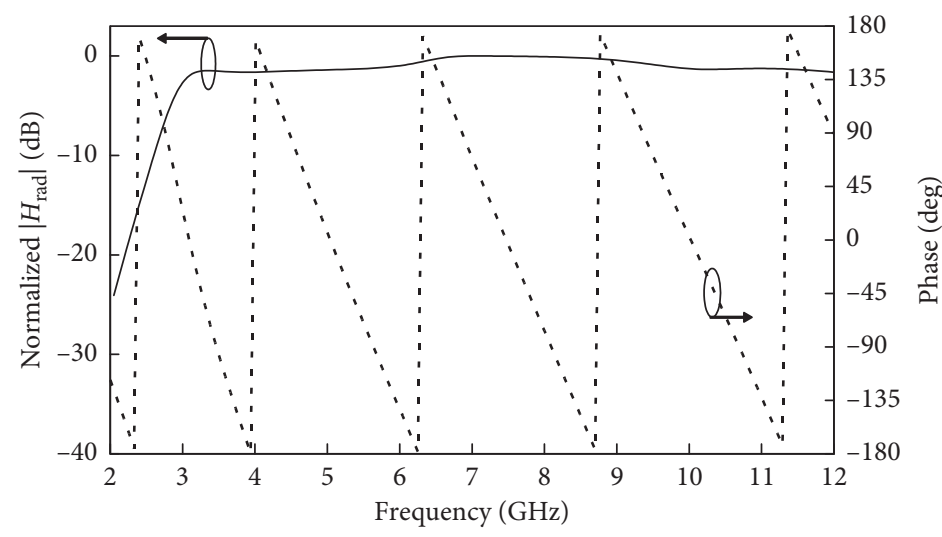

Figure 15: Simulated $\left|H_{\text {rad }}\right|$ of the antenna in the boresight direction.

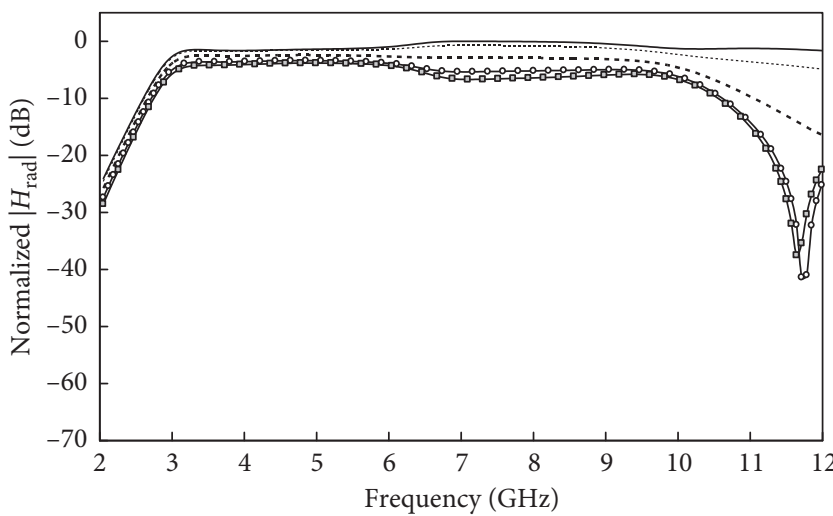

$$
\begin{aligned}
-\theta & =0 \operatorname{deg} \text { (H-plane) } \quad \cdots \quad \ldots \theta=20 \mathrm{deg} \text { (H-plane) } \\
\ldots \theta \theta & =40 \mathrm{deg} \text { (H-plane) } \\
\longrightarrow \theta & =80 \mathrm{deg} \text { (H-plane) }
\end{aligned}
$$

FIgURE 16: Simulated $\left|H_{\text {rad }}\right|$ of the antenna at various positions on H-plane in the right or left direction. 


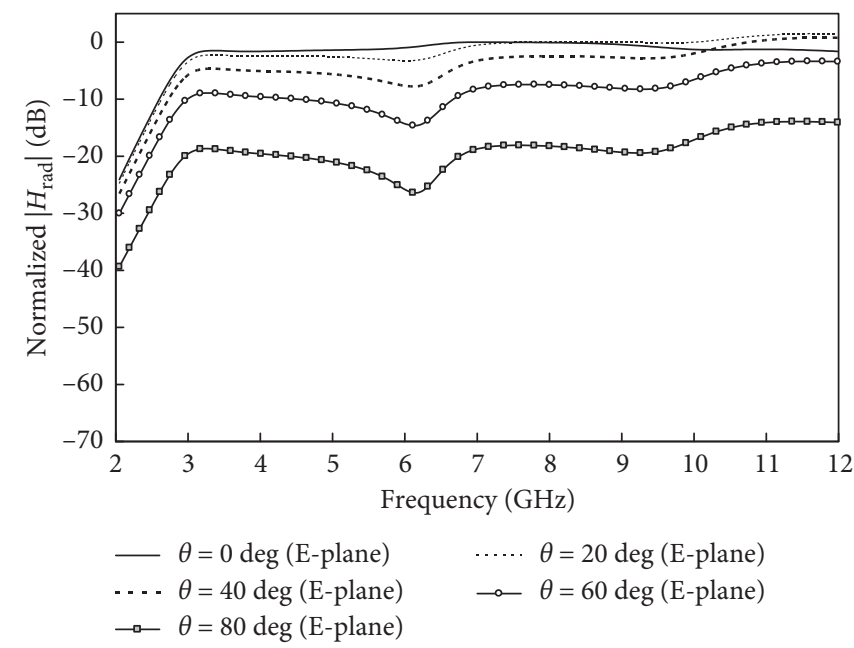

FIgURE 17: Simulated $\left|H_{\text {rad }}\right|$ of the antenna at various positions on E-plane in the upward direction.

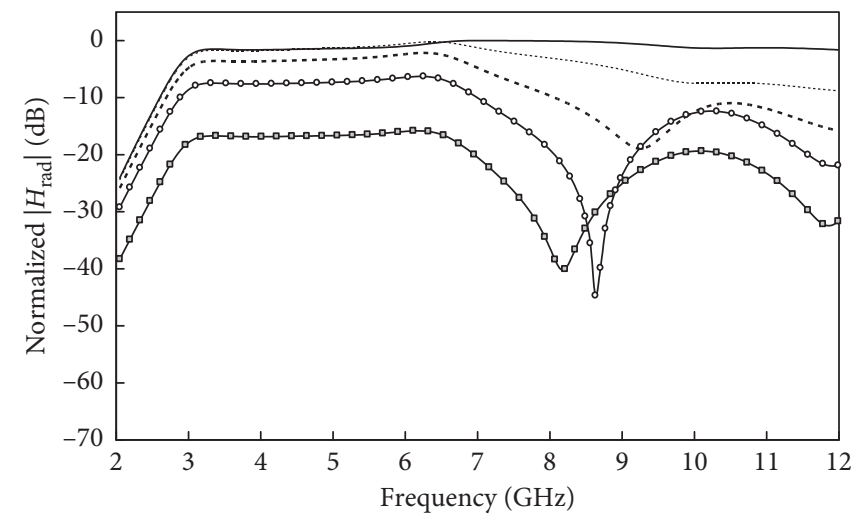

$$
\begin{aligned}
-\theta & =0 \operatorname{deg} \text { (E-plane) } \quad \cdots \cdots \theta=-20 \operatorname{deg} \text { (E-plane) } \\
\ldots-\theta & =-40 \operatorname{deg} \text { (E-plane) } \quad \multimap \theta=-60 \operatorname{deg} \text { (E-plane) } \\
\multimap-\theta & =-80 \operatorname{deg} \text { (E-plane) }
\end{aligned}
$$

FIGURE 18: Simulated $\left|H_{\text {rad }}\right|$ of the antenna at various positions on E-plane in the downward direction.

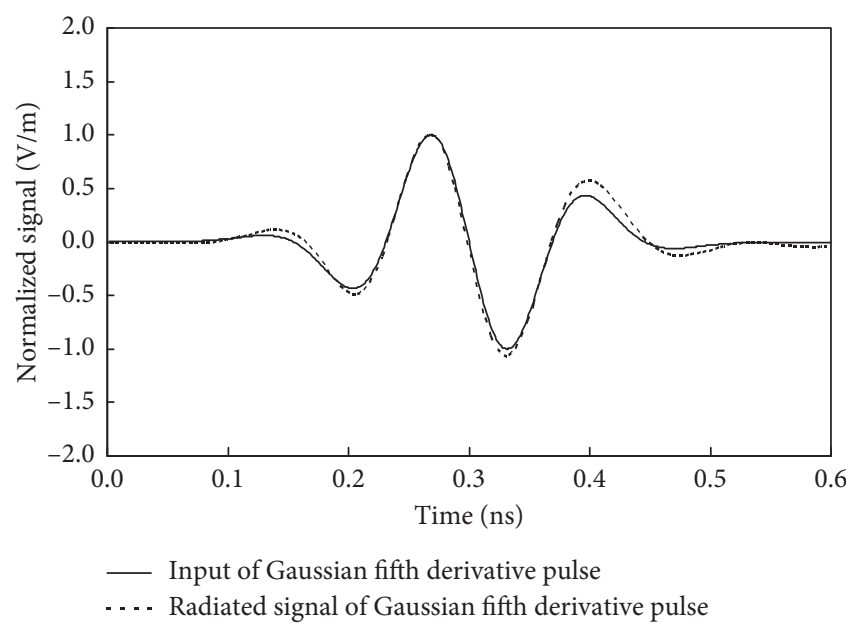

(a)

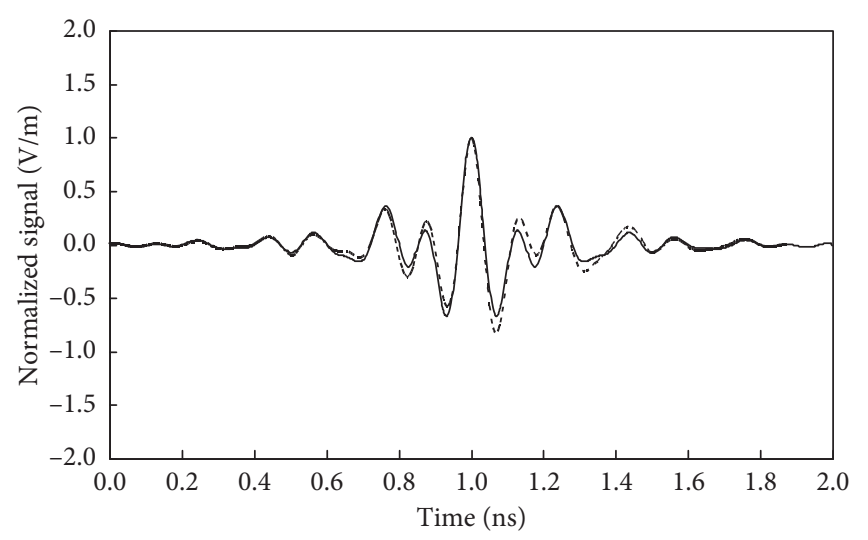

- Input of modulated Gaussian pulse with $6 \mathrm{GHz}$ band rejection .... Radiated signal of modulated Gaussian pulse with $6 \mathrm{GHz}$ band rejection

(b)

FIGURE 19: Waveforms of the input pulse superimposed on the radiated pulse. (a) Signals of the fifth-order derivative Gaussian pulse. (b) Signals of the modulated Gaussian pulse with $6 \mathrm{GHz}$ band rejection. 
TABLE 4: Correlation factors $(\rho)$ between the amplitudes of input and radiated signals.

\begin{tabular}{lc}
\hline Pulse types & $\rho$ \\
\hline Fifth-order derivative Gaussian pulse & 0.98 \\
Modulated Gaussian pulse with $6 \mathrm{GHz}$ band rejection & 0.93 \\
\hline
\end{tabular}

to the induction of electric fields in the area between the top of the CDM and the elliptical ring. In Figure 18, the pulse distortion in E-plane in the downward direction became worse beyond $6.5 \mathrm{GHz}$ as the electric fields in the area between the feeding point and the connector were induced.

The 5th-order derivative Gaussian pulse [22] and modulated Gaussian pulse with $6 \mathrm{GHz}$ band rejection [23] were used to assess the transmitting performance of the UWB antenna. From the FCC-EIRP-aware UWB pulse generator (PG) design approach in [24], it is evident that a 5th-derivative Gaussian PG has a very short UWB pulse width that is required in PG design. The 5th-order Gaussian pulse is the best fit for IR-UWB. In addition, based on the actual implementation using the foundry $0.18 \mu \mathrm{m}$ CMOS process [25], the 5th-order Gaussian pulse is ideal for IRUWB impulse signals.

The simulation was carried out by positioning the probe 3 meters away from the transmitting antenna. The electric fields received by the probe were measured in the boresight direction. In general, variations in the propagation distance affect the signal amplitude and time delay. However, since the amplitude was normalized, the propagation distance could be ignored. Figures 19(a) and 19(b) illustrate the input pulses in the time domain and the normalized electric fields for the fifth-order derivative Gaussian pulse and modulated Gaussian pulses with $6 \mathrm{GHz}$ band rejection, with the corresponding correlation factors $(\rho)$ tabulated in Table 4 . The small discrepancies between the input and radiated pulses correspond to the simulated $\left|H_{\text {rad }}\right|$ in the boresight direction (Figure 15).

\section{Conclusions}

This study proposes an elliptical ring antenna excited by a circular disc monopole. The proposed antenna could achieve ultra-wideband and bidirectional radiation characteristics in the 3.1-10.6 GHz frequency range. The antenna gain and $\left|H_{\mathrm{rad}}\right|$ are sufficiently flat with linear phase response over the UWB spectrum. In addition, the correlation factors $(\rho)$ between the input and radiated pulses for the fifth-order derivative Gaussian pulse and modulated Gaussian pulse with $6 \mathrm{GHz}$ band rejection are 0.98 and 0.93 , respectively. The CDM-excited elliptical ring antenna possesses several attractive characteristics, including economy, compactness, and ease of fabrication with a gain of $3.9 \mathrm{dBi}$. The antenna is suitable for UWB communications.

\section{Data Availability}

The data used to support the findings of this study are available from the corresponding author upon request.

\section{Conflicts of Interest}

The authors declare that there are no conflicts of interests regarding the publication of this paper.

\section{Acknowledgments}

This work was supported by the Thailand Research Fund under contract no. MRG5280210.

\section{References}

[1] C. Saha, J. Y. Siddiqui, and Y. M. M. Antar, Multifunctional Ultrawideband Antennas: Trends, Techniques and Applications, CRC Press, Boca Raton, FL, USA, 2019.

[2] US Federal Communications Commission (FCC), 2003, http://www.fcc.gov/oet/info/rules.

[3] K. Ghaemi and N. Behdad, "A low-profile, vertically polarized ultrawideband antenna with monopole-like radiation characteristics," IEEE Transactions on Antennas and Propagation, vol. 63, no. 8, pp. 3699-3705, 2015.

[4] Y. Shi, A. K. Amert, and K. W. Whites, "Miniaturization of ultrawideband monocone antennas using dielectric loading," IEEE Transactions on Antennas and Propagation, vol. 64, no. 2, pp. 432-441, 2016.

[5] Y. Zhao, Z. Shen, and W. Wu, "Wideband and low-profile monocone quasi-Yagi antenna for endfire radiation," IEEE Antennas and Wireless Propagation Letters, vol. 16, pp. 325328, 2017.

[6] C. Xie, J. Yin, X. Li, F. Pang, Q. Liu, and J. Yang, "An ultrawideband dipole with a director as a feed for reflector antennas," IEEE Antennas and Wireless Propagation Letters, vol. 16, pp. 1341-1344, 2017.

[7] J. Ha, M. A. Elmansouri, and D. S. Filipovic, "A compact ultrawideband reflector antenna: using a wide-band omnidirectional antenna with a mechanically steerable endfire beam to illuminate a half-cut paraboloid reflector," IEEE Antennas and Propagation Magazine, vol. 60, no. 3, pp. 75-86, 2018.

[8] D. Yang, J. Hu, and S. Liu, "A low profile UWB antenna for WBAN applications," IEEE Access, vol. 6, pp. 25214-25219, 2018.

[9] R. Lian, T.-Y. Shih, Y. Yin, and N. Behdad, "A high-isolation, ultra-wideband simultaneous transmit and receive antenna with monopole-like radiation characteristics," IEEE Transactions on Antennas and Propagation, vol. 66, no. 2, pp. 1002-1007, 2018.

[10] S. S. Zhekov, A. Tatomirescu, and G. F. Pedersen, "Antenna for ultrawideband channel sounding," IEEE Antennas and Wireless Propagation Letters, vol. 16, pp. 962-965, 2017.

[11] I. B. Vendik, A. Rusakov, K. Kanjanasit, J. Hong, and D. Filonov, "Ultrawideband (UWB) planar antenna with single-, dual-, and triple-band notched characteristic based on electric ring resonator," IEEE Antennas and Wireless Propagation Letters, vol. 16, pp. 1597-1600, 2017.

[12] S. Nikolaou and M. A. B. Abbasi, "Miniaturization of UWB antennas on organic material," International Journal of Antennas and Propagation, vol. 2016, Article ID 5949254, 12 pages, 2016.

[13] D. Zhao, C. Yang, M. Zhu, and Z. Chen, "Design of WLAN/ LTE/UWB antenna with improved pattern uniformity using ground-cooperative radiating structure," IEEE Transactions on Antennas and Propagation, vol. 64, no. 1, pp. 271-276, 2016. 
[14] S. Nikolaou and M. A. B. Abbasi, "Design and development of a compact UWB monopole antenna with easily-controllable return loss," IEEE Transactions on Antennas and Propagation, vol. 65, no. 4, pp. 2063-2067, 2017.

[15] G. Cappelletti, D. Caratelli, R. Cicchetti, C. Gennarelli, M. Simeoni, and O. Testa, "A low-profile reflector-enhanced drop-shaped printed antenna for wide-band wireless communications," International Journal of Antennas and Propagation, vol. 2017, Article ID 7196765, 12 pages, 2017.

[16] M. I. Khan, M. I. Khattak, G. Witjaksono et al., "Experimental investigation of a planar antenna with band rejection features for ultra-wide band (UWB) wireless networks," International Journal of Antennas and Propagation, vol. 2019, Article ID 2164716, 11 pages, 2019.

[17] M.-C. Tang, T. Shi, and R. W. Ziolkowski, "Planar ultrawideband antennas with improved realized gain performance," IEEE Transactions on Antennas and Propagation, vol. 64, no. 1, pp. 61-69, 2016.

[18] B. Yeboah-Akowuah, P. Kosmas, and Y. Chen, "A Q-slot monopole for UWB body-centric wireless communications," IEEE Transactions on Antennas and Propagation, vol. 65, no. 10, pp. 5069-5075, 2017.

[19] L. Y. Nie, X. Q. Lin, Z. Q. Yang, J. Zhang, and B. Wang, "Structure-shared planar UWB MIMO antenna with high isolation for mobile platform," IEEE Transactions on Antennas and Propagation, vol. 67, no. 4, pp. 2735-2738, 2019.

[20] CST ${ }^{\circledR}$ Microwave Studio, Quick Start Guide, 2019.

[21] H. G. Schantz, The Art and Science of Ultrawideband Antennas, Artech House, Norwood, MA, USA, 2005.

[22] C.-C. Lin, Y.-C. Kan, L.-C. Kuo, and H.-R. Chuang, "A planar triangular monopole antenna for UWB communication," IEEE Microwave and Wireless Components Letters, vol. 15, no. 10, pp. 624-626, 2005.

[23] M. Ghavami, Ultra Wideband Signals and Systems in Communication Engineering, John Wiley \& Sons, Hoboken, NJ, USA, 2004.

[24] X. Wang, B. Qin, H. Xie et al., "FCC-EIRP-aware UWB pulse generator design approach," in Proceedings of the IEEE International Conference on Ultra-Wideband, pp. 592-596, Vancouver, Canada, September 2009.

[25] X. Wang, S. Fan, B. Qin et al., “A 0.05 pJ/p-mV 5th-derivative pulse generator for full-band IR-UWB transceiver in $0.18 \mu \mathrm{m}$ CMOS," in Proceedings of the IEEE Radio and Wireless Symposium, pp. 70-73, Phoenix, AZ, USA, January 2011. 